\title{
Firing Simulation Studies of Household Porcelain in Shuttle Kilns
}

\author{
Z.Z. Zhang \\ Mechanical and Electrical Engineering College \\ Jingdezhen Ceramic Institute \\ Jingdezhen, China
}

\author{
J.H. Feng \\ Mechanical and Electrical Engineering College \\ Jingdezhen Ceramic Institute \\ Jingdezhen, China
}

\author{
W.G. Liu \\ Mechanical and Electrical Engineering College \\ Jingdezhen Ceramic Institute \\ Jingdezhen, China
}

\begin{abstract}
This paper aims at the sintering technological process in the trial-production of household porcelain, which simulates the firing process of household porcelain (bowl for example) by using 3D simulation software (FLUENT6.3), for different flow rates of the burner to simulate different shape/position size pressure distribution and temperature distribution of products in the kiln, so as to explore and analyze the digital simulation technology law in the application of porcelain firing. The firing simulation research results can provide enterprises with an important basis of some numerical and theoretical analysis.
\end{abstract} kiln

Keywords-household porcelain; firing fluent simulation; shuttle

\section{INTRODUCTION}

At present, China household porcelain production has basically achieved electrification, automation and modernization, but the firing equipment is commonly the shuttle kiln and tunnel kiln. The firing pass rate is less than 90 percent, and changing the firing products requires the use of trial burn approach by defect analysis to improve the firing process and guarantee the production. For a variety of firing defective products, enterprises can no longer get comprehensive use of the actual production, so they have to return to the front-end process. The loss is large. This paper attempts to simulate the state of the firing process of household porcelain (bowl for example) by using FLUENT6.3 software. Through simulation analysis of the flow rate of the burner, furnace internal pressure distribution, and other aspects of the distribution of temperature field, this paper explores the state of the firing process of the household porcelain and parameters change. For example, from national standards of household porcelain, from simulating temperature and pressure field uniformity we can determine the products firing defects problems (diameter, height, flatness deformation detection, etc.), so as to provide a theoretical and data basis for guiding production.

\section{MODELING AND PARAMETER SELECTION}

\section{A. Geometric Model Size}

The finite element model geometry in this paper uses a household shuttle kiln in a certain Jingdezhen ceramics factory as an example. Its products are the conical bowl, the size is $10 \mathrm{~cm} * 2 \mathrm{~cm} * 10 \mathrm{~cm}$ (big mouth diameter*small mouth diameter* bowl highness), the effective size of the kiln firing space (kiln car tops above dimensions) is $210 \mathrm{~cm}^{*} 160 \mathrm{~cm} * 120 \mathrm{~cm}$, products piling code is four layers, the height is $25 \mathrm{~cm}$, the number of products in each layer is 48 , spacing of each product is $25 \mathrm{~cm}$, the size of the burner is simplified to a cylinder ( $6 \mathrm{~cm}$ in diameter, $10 \mathrm{~cm}$ in length), five in each row, symmetrical distribution, kiln exhaust pipe's diameter is $30 \mathrm{~cm}$.

\section{B. Model Assumptions}

1) Kiln thermal and radiation losses are negligible; 2) ignore product thickness and internal chemical reaction heat; 3 ) high temperature flue gas temperature fluctuations are ignored in the process of change, such as the dynamic time lag.

\section{Parameter Selection}

TABLE I. LPG COMPONENTS

\begin{tabular}{|l|l|l|l|l|l|l|l|}
\hline Components. & $\mathrm{CH} 4.1$ & $\begin{array}{l}\mathrm{C} 2 \mathrm{H} 4 .+ \\
\mathrm{C} 2 \mathrm{H} 6.1\end{array}$ & $\mathrm{C} 3 \mathrm{H} 6.1$ & $\mathrm{C} 3 \mathrm{H} 8.1$ & C4H8.1 & C4H10. & other.7 \\
\hline Volume ratio. & 0.1 & 0.1 & 19.95 .1 & 76.18 .1 & 0.1 & 3.87 .1 & 0.1 \\
\hline
\end{tabular}

Take the excess air coefficient $\alpha=1.1$, smoke density $\rho=$ $1.26 \mathrm{~kg} / \mathrm{m}^{3}$; when provisional maximum firing temperature $\mathrm{t}=$ $1350{ }^{\circ} \mathrm{C}, \mathrm{C} 1=1.58 \mathrm{KJ} / \mathrm{m}^{3}{ }^{\circ} \mathrm{C}$; when flue gas temperature $\mathrm{t}=$ $100{ }^{\circ} \mathrm{C}, \mathrm{C} 2=1.38 \mathrm{KJ} / \mathrm{m}^{3}{ }^{\circ} \mathrm{C}$, flue gas heat capacity $\mathrm{c}=1.48$ $\mathrm{KJ} / \mathrm{m}^{3}{ }^{\circ} \mathrm{C}$, dynamic viscosity $\mathrm{v}=1.79 \mathrm{e}-5$, convective heat transfer coefficient a is a $116 \mathrm{~W} / \mathrm{m}^{2} \mathrm{k}$, heat units $\mathrm{q}$ takes $400 \mathrm{~W} / \mathrm{m}^{2}$ tentative kiln temperature Tw is $700{ }^{\circ} \mathrm{C}$, blackness 0.3 , the system comes with various other parameters selected physical parameters of the default values.

To enhance heat transfer, to improve thermal efficiency and to reduce temperature, shuttle kiln burner is equipped with high-speed burners, flue gas for incompressible viscous Newtonian fluid, the choice of second-order upwind steady turbulent flow problems by instantaneous processing ${ }^{[1-2]}$, using absolute speed formula, numerical model selection criteria $\mathrm{k}-\varepsilon$ model with coupled implicit method, in order to ensure convergence, the temperature relaxation factor is 0.8 , velocity, pressure, turbulence and turbulent dissipation 
relaxation factor is 0.5 , import turbulence disorder degree is 0.05 , fluid properties and inertial relaxation factor with default values.

Set model selection composite heat transfer model boundary conditions, boundary conditions, shuttle kiln burner flue gas flow rate used is generally between $20-100 \mathrm{~m} / \mathrm{s}$, the speed of the model selection imports (respectively $50 \mathrm{~m} / \mathrm{s}$, $80 \mathrm{~m} / \mathrm{s}$ ), using fluent ${ }^{[3-4]}$ before processing software gambit to establish geometry, figure1.

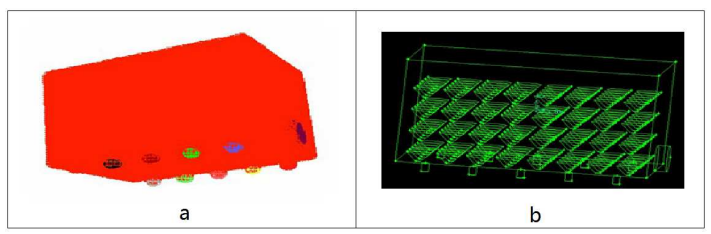

FIGURE I. GEOMETRIC MODEL

a: The burner jet velocity is $50 \mathrm{~m} / \mathrm{s}$.

b: The burner jet velocity is $80 \mathrm{~m} / \mathrm{s}$.

\section{Simulation EXPERIMENT RESUltS AND ANALYSIS}

A. The Kiln Burner and Heat Flow Field Simulation Results

Burner jet velocity is $50 \mathrm{~m} / \mathrm{s}$ and $80 \mathrm{~m} / \mathrm{s}$, the kiln burner and heat flow field simulation results are shown in figure 2 .

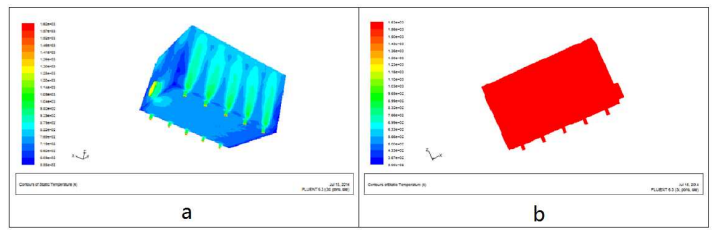

FIGURE II. THE KILN BURNER AND HEAT FLOW FIELD SIMULATION RESULTS

a: The burner jet velocity is $50 \mathrm{~m} / \mathrm{s}$.

b: The burner jet velocity is $80 \mathrm{~m} / \mathrm{s}$.

From the above two simulated heat field of flow velocity, by increasing the jet velocity of the burner, obviously you can see temperature field's temperature in Figure 2 tends to be more stable and closer to the maximum firing temperature, indicating the development trend in the actual production of household porcelain from traditional self-priming burner to power burner. You can make the furnace temperature in the interior space even and fast approaching the firing temperature. By enhancing convective heat transfer, heat transfer can be improved, the simulation test is desirable whether in theory or in practice. But for large volume shuttle kiln, according to the law of the vertical airflow, the flame rising height is limited, only by increasing the flow rate in the burner so as to achieve even temperature in the kiln is unscientific, and if with bare bright flame burning and power burner speed erosion, it may lead to products falling dirty or deformed red rinse hot gas pressure deformation as a result of firing defects, which requires fuel to be completely clean and complete combustion and burner layout and flow should be considered. The law of symmetrical arrangement of temperature distribution of flow field in the burner is shown in figure 3.
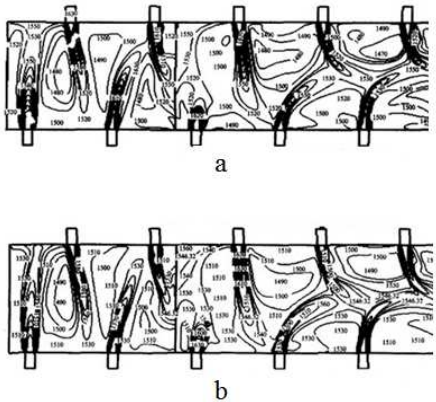

FIGURE III. THE LAW OF SYMMETRICAL ARRANGEMENT OF TEMPERATURE DISTRIBUTION OF FLOW FIELD IN THE BURNER

a: The burner jet velocity is $50 \mathrm{~m} / \mathrm{s}$.

b: The burner jet velocity is $80 \mathrm{~m} / \mathrm{s}$.

From the above graph drawn, high velocity burners staggered arrangement is more uniform in the heat flow field, it should be combined with the burner arrangement, such as alternative and hierarchical arrangement mode, so as to make better uniformity of heat to guarantee firing high-quality products.

\section{B. Isotherm Simulation Results of Heat Flow Field in the Kiln}

Isotherm simulation results of heat flow field in the kiln are shown in figure 4.

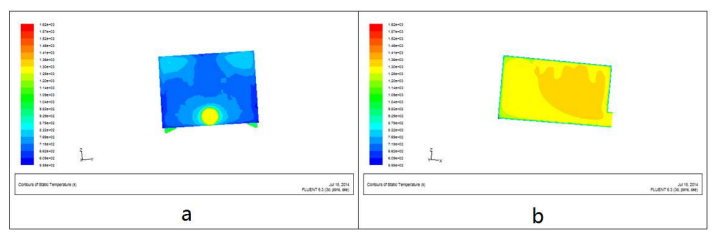

FIGURE IV. ISOTHERM SIMULATION RESULTS OF HEAT FLOW FIELD IN THE KILN

a: The burner jet velocity is $50 \mathrm{~m} / \mathrm{s}$.

b: The burner jet velocity is $80 \mathrm{~m} / \mathrm{s}$.

You can see from isotherm simulation results of heat flow field in the kiln, inside a shuttle kiln, there is a small area from the kiln car surface to the top of the kiln, the temperature there is lower than the other isotherm shown, in the actual production, there exists raw burned area of products certainly. In other areas, burning problems exist. That's because this area has something to do with the kiln structure or with the piling of the products. The approach to solve this problem is to improve the kiln by changing the kiln's inside width or changing the kiln's height. Regardless of any method, the firing will affect the yield and the approach is not desirable. But in actual production, appropriate piling requires dense top and sparse bottom; to make the kiln's dome structure become flattened structure is a good way to improve production so as to promote production efficiency. Or from the perspective of process recipe, using different kiln firing space, laying products of different formulations or temperature firing system, for example, in this area firing small spoons or hypocalcemia class products of mineral raw materials formulations, you can reduce the maximum firing temperature, the temperature lower 
than $1350^{\circ} \mathrm{C}$ can be fired. This can flexibly and effectively circumvent or make good use of this area.

\section{Kiln Pressure field Simulation}

Take the Z-axis XY plane kiln pressure field simulation, the results are shown in figure 5.

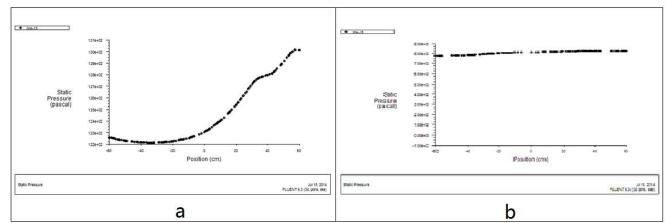

FIGURE V. RESULTS OF KILN PRESSURE FIELD SIMULATION

a: The burner jet velocity is $50 \mathrm{~m} / \mathrm{s}$.

b: The burner jet velocity is $80 \mathrm{~m} / \mathrm{s}$.

From the kiln pressure field simulation results analysis in graph 1 (velocity $50 \mathrm{~m} / \mathrm{s}$ ) and graph 2 (velocity $80 \mathrm{~m} / \mathrm{s}$ ), with the improvement of the burner jet velocity, pressure field is gradually stabilizing, the trend of thermal deformation of the firing product is good, you can improve the heat transfer intensity, speed firing, and will help to improve the big drawbacks of energy consumption. The premise is that highpressure press is a must, the green body is suitable for punching out, and will inevitably result in significant loss of mechanical energy and improve the mechanical strength. While the kiln pressure is high, tightness of the furnace and thermal shock resistance is poor, in turn, prompted the instability of firing. High kiln positive pressure can cause leakage fire, huge heat loss. If you changed the exhaust port on the top, according to the law of the vertical airflow, the hot flue gas is discharged faster directly from the top, causing more heat loss, so you can use the kiln bottom for the mainstream smoke, and even use the kiln wall exhaust way, so as to make heat flow field uniform quickly, improve the drawback of deformation of the product's shape and size due to uneven heating. So the method of only improving the kiln firing system in terms of unilateral pressure is not desirable, it must be combined with other control methods.

\section{Kiln Temperature Field Simulation}

Take the Z-axis XY plane kiln temperature field simulation, the results are shown in figure 6.

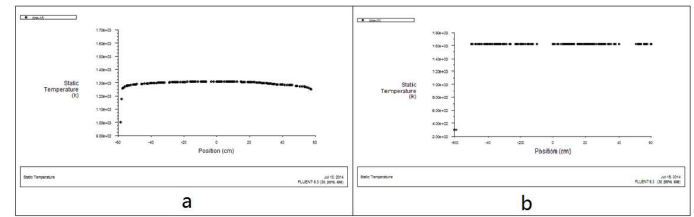

FIGURE VI. THE TEMPERATURE DISTRIBUTION ALONG THE Z AXIS XY PLANE

a: The burner jet velocity is $50 \mathrm{~m} / \mathrm{s}$.

b: The burner jet velocity is $80 \mathrm{~m} / \mathrm{s}$.

From the comparison of kiln temperature field simulation results in figure 1 (flow rate: $50 \mathrm{~m} / \mathrm{s}$ ) and figure 2 (flow rate: $80 \mathrm{~m} / \mathrm{s}$ ): along the Z-axis XY plane, there is little difference of geometry between household porcelain. When the kiln space and the shed board layers are fixed, there is little change in the overall flow of hot flue and the temperature is higher and shows a steady uniform in the temperature fields at a flow rate of $80 \mathrm{~m} / \mathrm{s}$. You can simulate the firing products of different shapes and sizes, which has little impact on the law of heat field mainstream transfer. This constitutes a powerful theoretical support for simulating different products to improve the quality of firing. From the comparison of the chart data, the average temperature in figure 2 is higher than that in figure 1, which plays a greater role in the green production of ceramic kiln, energy saving, even firing, reducing defects and other aspects of the firing. Of course, only increasing the flow rate to improve the quality of the firing is not desirable, it must be combined with the process and the actual production needs.

\section{CONCLUSIONS}

Through the firing process simulation study of household porcelain and compared with the latest national standard of household porcelain, in terms of burner's velocity, kiln space pressure distribution, temperature field distribution of products and the firing defect factors caused by the firing process' temperature, pressure, flow rate, the authors draw the following conclusions based on the results of the comparative analysis above:

1) Improving burner flame velocity can enhance the uniformity of kiln temperature field, heat transfer effect. It can also improve the quality of firing and promote energy conservation. If clean energy is used combined with other methods, such as burner layout, the effect is much better.

2) Firing system and reasonable processes should be considered from the perspective of different type of kiln, firing space shape and size, product piling method and different process recipes, so that the firing process become more scientific and reasonable.

3) Kiln pressure distribution and uniformity depend on the location of the exhaust port. High-speed thermostat burner should be used mainly to strengthen the hot flue gas heat transfer. Exhaust smoke should mainly be emitted from the kiln bottom, or from the kiln wall. If both methods are in combination, they can promote high quality firing of the products.

4) The simulation results and laws are in line with the results calculated by combustion, heat transfer ${ }^{[5-7]}$, and hydrodynamic theory.

\section{PROSPECTS}

Compared with household porcelain GB/T 3532-2009 and a series of criteria to judge the qualified products, software Fluent only has made the focus of research on the law of the heat flow field, pressure field distribution in the process of firing of household porcelain in shuttle kilns and provided the basis for judgments of firing defects (flatness, compositional heterogenity) as well as other simulation studies of energy saving. But is it suitable to determine whether the product is qualified or not in thermal shock resistance, water absorption, whiteness, compressive flexural strength? Also in guiding the actual production, it should be combined with theoretical calculations of other software (such as ansys simulation 
software, animation software, expert systems, Pro/E, etc.) for online simulation testing, which requires our research group's in-depth study and practice.

\section{REFERENCES}

[1] Liu Linhua, Yu Qizheng, Ruan Liming. Turbulence Effect on Radiative Transfer - Turbulence Radiation Model, Combustion Science and Technology :3 (3),pp.229-233,1997.

[2] SAZHIN SS, SAZHINA EM, FALTSI-SARAVELOUO, The P-1 Model for thermal radiation transfer, Advantages and limitations Fuel: 75 (3),pp.289-294,1996.

[3] Zhanzhong, Wang Jing, Lan Xiaoping. FLUENT Fluid Engineering Simulation Examples and Application ,Beijing Institute of Technology Press: Beijing, 2004.

[4] Yu Yong.FLUENT Entry and Advanced Tutorial ,Beijing Institute of Technology Press: Beijing,2008.

[5] Zhang Quan, Liao Qingqing, Wu Huiming, Cai Junlin .The Study of Shuttle Kiln Flue Gas Temperature Measuring Device, Chinese Test Technology: Volume 2 of Issue 33 in March 2007.

[6] GANESAN P, LOGANATHAN P. Radiation and mass transfer effects on flow of an incompressible viscous fluid past a moving vertical cylinder , International Journal of Heat and Mass Transfer:45,pp.4281$4288,2002$.

[7] [Yang Shiming, Tao Wenling. Heat Transfer third edition ,Beijing Higher Education Press: 1998. 